\title{
ANALISA USER EXPERIENCE PADA SISTEM INFORMASI AKADEMIK UNIVERSITAS PENDIDIKAN GANESHA DITINJAU DARI PENGGUNA MAHASISWA
}

\author{
Dewa Ayu Putu Ari Widhiani ${ }^{1}$, I Ketut Resika Arthana ${ }^{2}$, I Made Ardwi Pradnyana ${ }^{3}$ \\ ${ }^{1}$ Fakultas Teknik dan Kejuruan, Universitas Pendidikan Ganesha \\ email: by.awidhiani@gmail.com \\ 2 Fakultas Teknik dan Kejuruan, Universitas Pendidikan Ganesha \\ email: resika.arthana@gmail.com \\ ${ }^{3}$ Fakultas Teknik dan Kejuruan, Universitas Pendidikan Ganesha \\ email: pradnyana.ardwi@gmail.com
}

\begin{abstract}
Abstrak
Penelitian ini bertujuan untuk mengetahui tingkat kepuasan pengguna dan mengevaluasi SIAK Undiksha ditinjau dari pengguna mahasiswa menggunakan metode Usability Testing dengan teknik Firstclick Usability Testing, Performance Measurement, Retrospective Think Aloud (RTA), kuisoner System Usability Scale (SUS) serta memberikan rekomendasi perbaikan terhadap sistem tersebut berdasarkan atas hasil penelitian. Ada beberapa aspek yang dikaji dalam penelitian ini yaitu efektivitas (effectiveness), efisiensi (efficiency), tingkat kesalahan (error), dan kepuasan pengguna (satisfaction) menggunakan SIAK Undiksha ditinjau dari pengguna mahasiswa. Populasi dari penelitian ini yaitu mahasiswa Undiksha dengan melibatkan 385 responden kuisioner SUS dan 20 orang responden usability testing. Hasil penelitian berdasarkan analisis Mann Whitney U-test dan SUS menunjukkan bahwa (1) SIAK Undiksha ditinjau dari pengguna mahasiswa sudah efektif akan tetapi masih terdapat beberapa error yang ditemukan dalam sistem, (2) SIAK Undiksha ditinjau dari pengguna mahasiswa sudah efisien dilihat dari tidak adanya perbedaan yang signifikan waktu pengerjaan tugas kelompok mahir dan kelompok pemula, dan (3) Pengguna merasa kurang puas menggunakan SIAK Undiksha ditinjau dari pengguna mahasiswa dilihat dari skor kuisioner SUS sebesar 61,6. Dengan demikian berdasarkan hasil analisis data tersebut disimpulkan bahwa SIAK Undiksha ditinjau dari pengguna mahasiswa sudah memenuhi kriteria usability baik akan tetapi pengguna belum puas saat menggunakan SIAK Undiksha ditinjau dari pengguna mahasiswa. Hal ini dapat dilihat pada penilaian tingkat efektivitas, efisiensi, tingkat kesalahan dan kepuasan pengguna, SIAK Undiksha ditinjau dari pengguna tersebut hanya berhasil memenuhi 2 dari 4 aspek. Oleh sebab itu, rekomendasi perbaikan dalam penelitian ini difokuskan untuk mengubah tata letak (layout) halaman dan menu navigasi sesuai hasil data penyebab kesalahan (error) pengguna dan menyederhanakan penggunaa Bahasa. Perbaikan dilakukan dengan membuat wireframe halaman utama SIAK Undiksha itinjau dari pengguna mahasiswa, halaman menu prosedur, halaman submenu biodata, halaman ubah biodata, halaman statistic nilai mahasiswa dan halaman cetak kartu rencana studi.
\end{abstract}

Kata-kata Kunci : analisa, user experience, efektivitas, efisiensi, tingkat kesalahan, kepuasan pengguna, SUS, wireframe.

\begin{abstract}
This study aims to determine the level of user satisfaction and evaluate SIAK Undiksha based on the review of the students using the Usability Testing. The techniques are First Click Usability Testing, Performance Measurement, Retrospective Think Aloud (RTA), Questionnaire System Usability Scale (SUS) and provide recommendations for improvement of the system based on the research results. There are several aspects that were examined in this study such as the effectiveness, efficiency, the error rate, and user satisfaction using SIAK Undiksha based on the review from the students. The population of this research is student Undiksha involving 385 SUS questionnaire respondents and 20 respondents usability testing. The results based on the analysis Mann Whitney U-test and SUS show that (1) SIAK Undiksha based on the students' review have been effective but there are still some errors found in the system, (2) SIAK Undiksha based on the students' review was already efficient as it was seen from the absence of time difference when performing tasks proficiently groups and novice group, and (3) users were dissatisfied using Undiksha SIAK seen in terms of student users of SUS questionnaire score of 61.6. Therefore, based on the results of the data analysis concluded that SIAK Undiksha based on the students' review have already met the criteria for usability good, but users are
\end{abstract}


not satisfied when using SIAK Undiksha terms of student users. It can be seen in the assessment of the level of effectiveness, efficiency, error rates and user satisfaction, in terms of user SIAK Undiksha only managed to meet two of the four aspects. Therefore, recommendations for improvement in this study focused on changing the layout of the page and navigation menu according to the results of data causes an error of users and simplify the language used. Repairs carried out by creating a wireframe main page SIAK Undiksha term of student users, page navigation procedures, bio sub menu page, change the Biodata page, statistics pages, and printed pages grades students' study plan card.

Keywords: analysis, user experience, effectiveness, efficiency, error rate, user satisfaction, SUS, wireframe.

\section{PENDAHULUAN}

Perkembangan teknologi semakin pesat dan banyak menunjukan kemajuan yang luar biasa. Hal tersebut semakin berpengaruh terhadap berbagai sektor kehidupan manusia. Salah satu pengaruhnya yaitu dalam bidang pendidikan, khususnya jenjang pendidikan tinggi. Penerapan perkembangan teknologi pada jenjang pendidikan tinggi ini contohnya yaitu Sistem Informasi Akademik. Sistem Informasi Akademik selain merupakan sumber daya informasi di kampus, juga dapat digunakan sebagai sarana media komunikasi antara dosen dan mahasiswa, mahasiswa dengan mahasiswa dosen dengan pejabat kampus terkait dan siapa saja yang ada di lingkungan kampus tersebut (Dian, 2008).

Salah satu Universitas yang menerapkan Sistem Informasi Akademik yaitu Universitas Pendidikan Ganesha. Sistem Informasi Akademik di Universitas Pendidikan Ganesha ini disebut dengan SIAK Undiksha. Dalam SIAK Undiksha ini terdapat beberapa macam pengguna yang diantaranya yaitu mahasiswa, dosen ataupun pegawai. Peneliti disini tertarik untuk meneliti SIAK Undiksha yang ditinjau dari pengguna mahasiswa karena dilihat dari segi peranan dari sistem ini. SIAK Undiksha yang ditinjau dari pengguna mahasiswa ini memiliki peranan yang sangat vital dalam hal administrasi mahasiswa baik itu informasi lengkap atau biodata mahasiswa, kartu rencana studi mahasiswa (KRS), kartu hasil studi mahasiswa (KHS), program pengalaman lapangan (PPL), dan data wisudawan. SIAK Undiksha yang ditinjau dari pengguna mahasiswa ini sendiri belum pernah dilakukan penelitian tentang user experience, jadi disini dipandang perlu melakukan penelitian user experience terhadap SIAK Undiksha yang ditinjau dari pengguna mahasiswa untuk mengetahui tingkat kepuasan pengguna dari SIAK Undiksha yang ditinjau dari pengguna mahasiswa.

Tujuan dari penelitian UX ini lebih berkaitan dengan rasa dan pengalaman yang dirasakan dan dialami oleh pengguna dengan produk yang digunakan. Perasaan yang dapat pengguna berikan sebagai hasil pengujian/evaluasi adalah: memuaskan, nyaman, menghibur, membantu, indah, kreatif, stumulasi kognitif, menyenangkan, lucu, mengejutkan, menantang, membosankan, membuat frustrasi, mengganggu (Lestari et al., 2016). UX menilai seberapa kepuasan dan kenyamanan seseorang terhadap sebuah produk, sistem, dan jasa. Sebuah prinsip dalam membangun UX adalah khalayak mempunyai kekuasaan dalam menentukan tingkat kepuasan sendiri (costumer rule). Seberapa pun bagusnya fitur sebuah produk, sistem, atau jasa, tanpa khalayak yang dituju dapat merasakan kepuasan, kaidah, dan kenyamanan dalam berinteraksi maka tingkat UX menjadi rendah (Wiryawan, 2011). Dengan melakukan evaluasi dengan pendekatan UX berfungsi untuk mengetahui apa yang dirasakan pengguna, apakah pengguna merasa senang, mendapatkan kemudahan, memiliki perasaan tertekan atau merasa puas ketika menggunakan sebuah sistem informasi akademik (Lestari et al., 2016).Peneliti mengambil aspek usability dalam penelitian user experience ini. Menurut Rubinoff dalam (Farida, L. D. 2016) mengatakan bahwa usability merupakan salah satu dari empat elemen dalam user experience, dimana usability tersebut mensyaratkan kemudahan 
pengguna terhadap komponen dan fitur yang ada pada sebuah situs.

Penelitian ini menggunakan metode usability testing yaitu dengan teknik Firstclick Usability Testing, Performance Measurement, Retrospective Think Alout (RTA) serta Kuisioner System Usability Scale (SUS). Teknik Firstclick Usability Testing ini digunakan untuk mengukur efektivitas dari SIAK Undiksha ditinjau dari pengguna mahasiswa, teknik Performance Measurement digunakan untuk mengukur tingkat efisiensi dan juga tingkat kesalahan (error), teknik Retrospective Think Aloud (RTA) dikombinasikan dengan kuisioner SUS untuk mengukur tingka kepuasan pengguna dan juga menjadi acuan untuk menyusun rekomendasi perbaikan.

Bertitik tolak dari uraian diatas dipandang perlu dilakukannya suatu penelitian tentang analisa user experience pada Sistem Informasi Akademik Universitas Pendidikan Ganesha untuk dapat mengetahui tingkat kenyamanan pengguna pada saat menggunakan sistem ini, maka dari itu peneliti melakukan penelitian yang berjudul "Analisa User Experience Pada Sistem Informasi Akademik Universitas Pendidikan Ganesha Ditinjau Dari Pengguna Mahasiswa".

\section{METODE}

Bagian ini akan menjelaskan mengenai tahapan dalam penelitian. Adapun tahap dalam penelitian ini seperti pada Gambar 1.

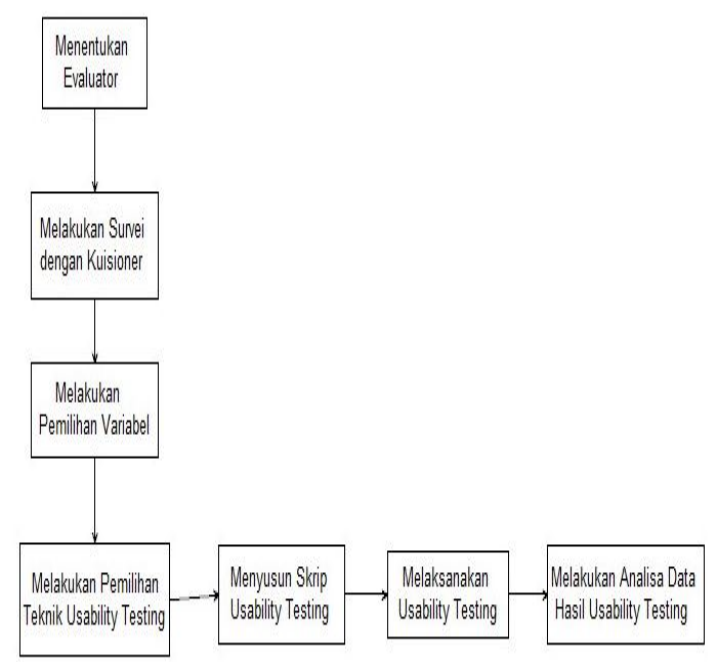

Gambar 1. Langkah Penelitian Adapun langkah-langkah dalam prosedur penelitian ini yaitu :

1. Menentukan Evaluator

Evaluator pengujian usability testing pada penelitian ini yaitu pengguna pemula dan pengguna mahir.

2. Melakukan Survei dengan Kuisioner

Melakukan pemilihan responden dengan kuisioner dan menggolongkannya berdasarkan pengguna pemula dan pengguna mahir.

3. Melakukan Pemilihan Variabel

Pemilihan variabel yang digunakan dalam penelitian, variabel yang digunakanantara lain efektifitas, efiesien, tingkat error dan juga tingkat kepuasan pengguna.

4. Melakukan Pemilihan Teknik Usability Testing

Pemilihan beberapa teknik dari usability testing yang sesuai dengan variabel yang telah dipilih. Teknik yang dipilih yaitu performance measurement yang digunakan untuk mengukur tingkat efisiensi dan error dari sistem. Teknik firstclick usability testing untuk mengukur tingkat efektifitas dari system dan teknik RTA serta kuisioner SUS untuk mengukur tingkat kepuasan pengguna.

5. Menyusun Skrip Usability Testing

Menyusun skrip usability testing yang akan dilakukan oleh pengguna pada saat melaksanakan usability testing.

6. Melaksanakan Usability Testing

Melaksanakan usability testing yang diawali dengan pengerjaan tugas yang diberikan oleh peneliti, selama pengerjaan 
tigas tersebut dilakukan teknik performance measurement dan teknik firstclick usability testing. Setelah pengerjaan tugas selesai maka akan dilakukan teknik RTA dan pengisian kuisioner SUS.

7. Melakukan Analisa Data Hasil Usability Testing

Melakukan analisis data yang telah didapatkan dari hasil usability testing.

\section{HASIL DAN PEMBAHASAN}

Untuk mengukur keefektifan dilakukan dengan mencari data kebenaran klik pertama pengguna. Sedangkan untuk mengukur keefisienan seperti yang telah dijelaskan sebelumnya hasil data akan dibandingkan antara kelompok pemula dan kelompok mahirdengan menggunakan uji statistic. Serta untuk mengukur kepuasan pengguna dilakukan dengan melakukan rekapitulasi hasil kuisioner dan dianalisis dengan perhitungan SUS.

Data yang diperoleh dari metode Usability Testing dengan teknik Performance Measurement diperoleh hasil data waktu pengerjaan tugas terhadap 20 orang responden. Data yang diperoleh dari teknik Firstclick Usability Testing diperoleh data ketepatan klikpertama responden pada saat pengerjaan setiap tugas yang diberikan oleh peneliti. Sedangkan data yang didapat dari proses usability testing dengan teknik RTA diperoleh hasil data berupa data masalah atau kesulitan saat menggunakan SIAK Undiksha ditinjau dari pengguna mahasiswa serta saran dari responden menunjukkan kesulitan atau masalah yang dialami responden saat menggunakan SIAK Undiksha ditinjau dari pengguna mahasiswa.

Adapun tugas yang peneliti berikan kepada responden yaitu seperti pada Tabel 1.

Tabel 1. Tugas yang diberikan peneliti kepada responden

\begin{tabular}{|c|l|}
\hline No & \multicolumn{2}{|c|}{ Instruksi } \\
\hline \multirow{2}{*}{1} & "Anda sekarang ada pada halaman \\
& $\begin{array}{l}\text { utama (dashboard) SIAK Mahasiswa } \\
\text { Undiksha dan Anda ingin mengubah }\end{array}$ \\
\hline
\end{tabular}

\begin{tabular}{|c|c|}
\hline No & \\
\hline & $\begin{array}{l}\text { salah satu isian data diri Anda yaitu } \\
\text { data alamat tinggal Anda menjadi Jalan } \\
\text { Udayana, Singaraja." }\end{array}$ \\
\hline 2 & $\begin{array}{l}\text { "Selanjutnya Anda ingin mencetak } \\
\text { biodata Anda." }\end{array}$ \\
\hline 3 & $\begin{array}{l}\text { "Anda kembali ke dashboard. Sekarang } \\
\text { Anda ingin melihat statistik nilai Anda } \\
\text { pada semester ganjil 2016/2017" }\end{array}$ \\
\hline 4 & $\begin{array}{l}\text { "Sekarang Anda ingin mencetak kartu } \\
\text { hasil studi pada semester ganjil } \\
\text { 2016/2017" }\end{array}$ \\
\hline 5 & $\begin{array}{l}\text { "Selanjutnya Anda ingin mengunduh } \\
\text { kutipan daftar nilai" }\end{array}$ \\
\hline 6 & $\begin{array}{l}\text { "Anda kembali ke dashboard. Sekarang } \\
\text { Anda ingin mencari tahu prosedur } \\
\text { perbaikan nilai" }\end{array}$ \\
\hline 7 & $\begin{array}{l}\text { "Sekarang Anda ingin mencetak kartu } \\
\text { rencana studi semester genap } \\
2016 / 2017 \text { yang telah Anda susun" }\end{array}$ \\
\hline 8 & $\begin{array}{l}\text { "Anda kembali ke dashboard. Sekarang } \\
\text { Anda ingin melihat prosedur wisuda." }\end{array}$ \\
\hline 9 & $\begin{array}{l}\text { "Selanjutnya Anda ingin mengunduh } \\
\text { contoh ijazah." }\end{array}$ \\
\hline 10 & $\begin{array}{l}\text { "Kini, Anda sudah mengeksplorasi SIAK } \\
\text { Mahasiswa Undiksha. Selanjutnya } \\
\text { Anda boleh keluar (logout) dari akun } \\
\text { Anda." }\end{array}$ \\
\hline
\end{tabular}

Dari hasil analisis ketepatan klik pengguna pada saat mengerjakan setiap tugas yang diberikan oleh peneliti, jadi jika responden tersebut benar melakukan klik pertama maka nilai keberhasilan penyelesaian tugas secara keseluruhan sebesar $87 \%$, dan jika responden tersebut salah melakukan klik pertama maka nilai keberhasilan penyelesaian tugas secara keseluruhan sebesar 46\% (Bailey, B. 2013). Peneliti disini menganalisis data ketepatan klik pertama pengguna dengan mencari rata-rata pengerjaan tugas responden pada tiap tugasnya sesuai 
dengan teori dari Bailey yaitu jika responden benar melakukan klik pertama maka nilainya sebesar $87 \%$ dan jika pengguna salah maka nilainya $46 \%$, lalu peneliti mencari rata-rata nilai setiap responden dan yang terakhir yaitu mencari rata-rata dari keseluruhan responden. Maka didapatkan hasil sebesar $\mathbf{7 9 \%}$.

Peneliti disini juga mencoba mencari data keefektifan dari data error yang dilakukan pengguna yaitu dimana efektifitas didapat dari jumlah tugas yang berhasil dilakukan dibagi dengan jumlah tugas yang dikerjakan lalu dikalikan dengan 100\% (Mifsud, J. 2015). Dari hasil analisis tersebut didapatkan hasil seperti pada Tabel 2.

Tabel 2. Analisis Efektivitas dari error pengguna

\begin{tabular}{|c|c|c|c|}
\hline $\begin{array}{l}\text { Kode } \\
\text { Resp. }\end{array}$ & $\begin{array}{c}\text { Jumla } \\
\text { h } \\
\text { Tugas } \\
\text { Selesa } \\
\text { i } \\
\text { denga } \\
\text { n } \\
\text { Sukse } \\
\text { s }\end{array}$ & $\begin{array}{c}\text { Jumlah } \\
\text { Tugas } \\
\text { yang } \\
\text { Dikerjak } \\
\text { an }\end{array}$ & $\begin{array}{c}\text { Presentas } \\
\text { e } \\
\text { Keefektifa } \\
n\end{array}$ \\
\hline RUP01 & 9 & 10 & $90 \%$ \\
\hline RUP02 & 8 & 10 & $80 \%$ \\
\hline RUP03 & 7 & 10 & $70 \%$ \\
\hline RUP04 & 10 & 10 & $100 \%$ \\
\hline RUP05 & 10 & 10 & $100 \%$ \\
\hline RUP06 & 9 & 10 & $90 \%$ \\
\hline RUP07 & 9 & 10 & $90 \%$ \\
\hline RUP08 & 9 & 10 & $90 \%$ \\
\hline RUP09 & 7 & 10 & $70 \%$ \\
\hline RUP10 & 8 & 10 & $80 \%$ \\
\hline $\begin{array}{c}\text { RUMO } \\
1\end{array}$ & 8 & 10 & $80 \%$ \\
\hline $\begin{array}{c}\text { RUMO } \\
2\end{array}$ & 9 & 10 & $90 \%$ \\
\hline $\begin{array}{c}\text { RUMO } \\
3\end{array}$ & 10 & 10 & $100 \%$ \\
\hline $\begin{array}{c}\text { RUMO } \\
4\end{array}$ & 9 & 10 & $90 \%$ \\
\hline $\begin{array}{c}\text { RUMO } \\
5 \\
\end{array}$ & 9 & 10 & $90 \%$ \\
\hline $\begin{array}{c}\text { RUMO } \\
6\end{array}$ & 9 & 10 & $90 \%$ \\
\hline $\begin{array}{c}\text { RUMO } \\
7\end{array}$ & 10 & 10 & $100 \%$ \\
\hline
\end{tabular}

\begin{tabular}{|c|c|c|c|}
\hline $\begin{array}{l}\text { Kode } \\
\text { Resp. }\end{array}$ & $\begin{array}{c}\text { Jumla } \\
\mathbf{h} \\
\text { Tugas } \\
\text { Selesa } \\
\mathbf{i} \\
\text { denga } \\
\mathbf{n} \\
\text { Sukse } \\
\mathbf{s}\end{array}$ & $\begin{array}{c}\text { Jumlah } \\
\text { Tugas } \\
\text { yang } \\
\text { Dikerjak } \\
\text { an }\end{array}$ & $\begin{array}{c}\text { Presentas } \\
\text { e } \\
\text { Keefektifa } \\
n\end{array}$ \\
\hline $\begin{array}{c}\text { RUM0 } \\
8\end{array}$ & 9 & 10 & $90 \%$ \\
\hline $\begin{array}{c}\text { RUM0 } \\
9\end{array}$ & 9 & 10 & $90 \%$ \\
\hline $\begin{array}{c}\text { RUM1 } \\
0 \\
\end{array}$ & 7 & 10 & $70 \%$ \\
\hline \multicolumn{3}{|c|}{ Rata-rata } & $88 \%$ \\
\hline
\end{tabular}

Dari kedua cara analisis tersebut didapatkan hasil efektivitas SIAK Undiksha ditinjau dari pengguna mahasiswa sebesar $79 \%$ dan $88 \%$, dapat dikatakan bahwa SIAK Undiksha ditinjau dari pengguna mahasiswa sudah efektif.

Untuk mengukur efisiensi pengerjaan tugas pada dilakukan dengan membandingkan waktu pengerjaan responden pemula dengan responden mahir pada hasil pengukuran usability $\mathrm{E}$ Learning Undiksha menggunakan Mann Whitney U-test. Hipotesis yang dipakai setiap tugas adalah sebagai berikut :

- HO : Tidak ada perbedaan waktu pengerjaan tugas pada kelompok responden pemula dan kelompok responden mahir.

$\mathrm{H} 1$ : Ada perbedaan waktu pengerjaan tugas pada kelompok responden pemula dan kelompok responden mahir.

Adapun hasil dari pvalue masing tugas yaitu seperti pada Tabel 3 .

Tabel 3. Pvalue tugas

\begin{tabular}{|c|c|}
\hline Tugas & pvalue \\
\hline 1 & 0,940 \\
\hline 2 & 0,731 \\
\hline 3 & 0,676 \\
\hline 4 & 0,237 \\
\hline 5 & 0,382 \\
\hline 6 & 0,721 \\
\hline 7 & 0,820 \\
\hline 8 & 0,186 \\
\hline 9 & 0,382 \\
\hline 10 & 0,701 \\
\hline
\end{tabular}


Untuk membuat kesimpulan pengolahan data ini setiap $p$-value masing-masing perbandingan pada setiap tugas dibandingkan dengan nilai $\alpha$ yang bernilai 0.05 . Apabila nilai $p$-valuenya lebih besar dari 0.05 maka keputusan yang diambil adalah tidak menolak $\mathrm{HO}$. Jadi dapat ditari kesimpulan bahwa secara statistik dari 10 tugas yang diberikan peneliti dapat dinyatakan tidak ada perbedaan signifikan waktu pengerjaan tugas reponden kelompok pemula dan kelompok mahir. Dari kesimpulan ini dapat diputuskan bahwa halaman SIAK Undiksha ditinjau dari pengguna mahasiswa sudah efisien.

Tingkat error dari SIAK Undiksha ditinjau dari pengguna mahasiswa ini didapat dari jumlah tugas yang tidak bisa dikerjakan oleh responden. Data tingkat error ini kemudian dianalisis dengan mencari rata-rata error yang dilakukan oleh semua responden baik itu responden pemula ataupun mahir sehingga didapatkan presentase error sebanyak $12,50 \%$. Adapun faktor penyebab kesalahan (error) pengguna yaitu seperti pada Tabel 4.

Tabel 4. Faktor penyebab kesalahan

\begin{tabular}{|c|c|c|}
\hline $\begin{array}{l}\text { Tuga } \\
\mathbf{s}\end{array}$ & $\begin{array}{l}\text { Kode } \\
\text { Resp. }\end{array}$ & $\begin{array}{c}\text { Penyebab } \\
\text { Kesalahan (error) }\end{array}$ \\
\hline $\begin{array}{c}\text { Tugas } \\
2\end{array}$ & $\begin{array}{l}\text { RUP06, } \\
\text { RUP08, } \\
\text { RUP09, } \\
\text { RUP10, } \\
\text { RUM08 }\end{array}$ & $\begin{array}{l}\text { Responden } \\
\text { kesulitan mencari } \\
\text { tombol cetak } \\
\text { biodata sehingga } \\
\text { langsung } \\
\text { melanjutkan ke } \\
\text { tugas selanjutnya. }\end{array}$ \\
\hline $\begin{array}{c}\text { Tugas } \\
3\end{array}$ & RUP09 & $\begin{array}{lr}\text { Responden } & \\
\text { kebingungan } & \text { pada } \\
\text { saat mencari } & \text { menu } \\
\text { statistik } & \text { nilai } \\
\text { karena } & \text { baru } \\
\text { beberapa } & \text { kali } \\
\text { menggunakan } & \\
\text { SIAK. } & \\
\end{array}$ \\
\hline $\begin{array}{c}\text { Tugas } \\
4\end{array}$ & $\begin{array}{l}\text { RUP02, } \\
\text { RUP03, } \\
\text { RUM01 } \\
\text { RUM06 }\end{array}$ & \begin{tabular}{lr}
\multicolumn{2}{l}{ Responden } \\
langsung & terfokus \\
pada & tugas \\
mencari & kutipan \\
daftar & nilai
\end{tabular} \\
\hline
\end{tabular}

\begin{tabular}{|c|c|c|}
\hline $\begin{array}{c}\text { Tuga } \\
\text { s }\end{array}$ & $\begin{array}{l}\text { Kode } \\
\text { Resp. }\end{array}$ & $\begin{array}{c}\text { Penyebab } \\
\text { Kesalahan (error) }\end{array}$ \\
\hline & RUM10 & $\begin{array}{lr}\text { sehingga tugas } \\
\text { mencetak kartu } \\
\text { hasil studi tersebut } \\
\text { langsung } \\
\text { dilewatkan. }\end{array}$ \\
\hline $\begin{array}{c}\text { Tugas } \\
5\end{array}$ & $\begin{array}{l}\text { RUP10, } \\
\text { RUM02 } \\
\text { RUM04 }\end{array}$ & $\begin{array}{l}\text { Responden } \\
\text { langsung } \\
\text { melanjutkan ke } \\
\text { tugas selanjutnya. }\end{array}$ \\
\hline $\begin{array}{c}\text { Tugas } \\
6\end{array}$ & $\begin{array}{l}\text { RUP01, } \\
\text { RUP02, } \\
\text { RUP03, } \\
\text { RUP07, } \\
\text { RUP09, } \\
\text { RUM01 } \\
\text { RUM05 } \\
\text { RUM09 } \\
\text { RU'ं10 }\end{array}$ & $\begin{array}{l}\text { Responden } \\
\text { kesulitan mencari } \\
\text { menu perbaikan } \\
\text { nilai yang berada } \\
\text { pada dashboard } \\
\text { sehingga } \\
\text { responden } \\
\text { kebingungan dan } \\
\text { langsung } \\
\text { melanjutkan ke } \\
\text { tugas berikutnya. }\end{array}$ \\
\hline $\begin{array}{c}\text { Tugas } \\
7\end{array}$ & RUM10 & $\begin{array}{l}\text { Responden } \\
\text { langsung } \\
\text { melanjutkan ke } \\
\text { tugas selanjutnya. }\end{array}$ \\
\hline $\begin{array}{c}\text { Tugas } \\
9\end{array}$ & RUP03 & $\begin{array}{ll}\text { Responden } & \text { awam } \\
\text { dengan } & \text { menu } \\
\text { wisudawan } & \\
\text { sehingga } & \text { tidak } \\
\text { berhasil } & \\
\text { mengunduh } & \\
\text { ijazah. } & \\
\end{array}$ \\
\hline
\end{tabular}

Berdasarkan Tabel 4 penyebab kesalahan terbanyak yang dialami oleh responden yaitu kesulitan mencari menu perbaikan nilai, responden yang mengalami hal tersebut sebanyak 9 responden. Perolehan niali untuk kuisioner SUS yaitu sebesar 61,6 , ini berarti skor tersebut lebih kecil dari skor standard SUS yaitu 68, sehingga dapat dikatakan bahwa responden kurang puas menggunakan SIAK Undiksha yang ditinjau dari pengguna mahasiswa. Berdasarkan hasil analisa dari kuisioner dengan skor kategori rendah yaitu dengan skor $>=40$ yaitu sebanyak 11 data kuisioner didapatkan bahwa hal yang membuat 
responden kurang puas menggunakan SIAK Undiksha ditnjau dari pengguna mahasiswa yaitu responden menyatakan bahwa tampilan SIAK Undiksha tidak konsisten dan perlu mempelajari banyak hal sebelum menggunakan SIAK Undiksha.

Rekomendasi perbaikan dilakukan dengan membuat wireframe dimana dasar yang digunakan dalam mengembangkan rekomendasi adalah panduan $\mathrm{HCl}$ dan hasil data usability testing yaitu performance measurement dan RTA. Adapun rekomendasi perbaikan dalam SIAK Undiksha ditinjau dari pengguna mahasiswa yaitu:

1. Rekomendasi Perbaikan Halaman Utama SIAK Undiksha ditinjau dari pengguna Mahasiswa

Perbaikan yang dilakukan pada halaman utama SIAK Undiksha ditinjau dari pengguna Mahasiswa adalah penyesuaian tampilan, perubahan bahasa dan istilah. Gambar 2 berikut merupakan rancangan wireframe halaman utama dari SIAK Undiksha ditinjau dari pengguna Mahasiswa.

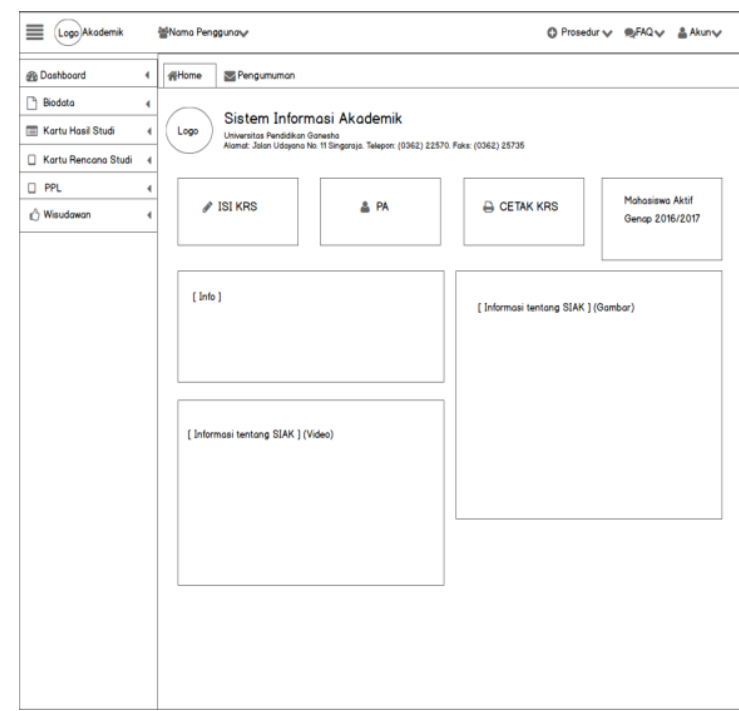

Gambar 2. Rancangan Wireframe Halaman Utama

Pada Gambar 4.2 tersebut yang menjadi rekomendasi perbaikan yaitu perubahan bahasa dan istilah pada halaman utama yang sebelumnya menggunakan bahasa Inggris kemudian dirubah menjadi bahasa Indonesia yaitu kata prosedur yang sebelumnya procedure dan akun yang sebelumnya account, sesuai dengan teori $\mathrm{HCl}$ yaitu suatu sistem harus konsisten dalam penggunaan bahasa (Andrews, 2017). SIAK Undiksha ditinjau dari pengguna mahasiswa harus konsisten dalam penggunaan bahasa yaitu Bahasa Indonesia. Rekomendasi perbaikan lain pada halaman utama yaitu perbaikan nilai dan perbaikan nama dihilangkan pada dashboard. Submenu perbaikan nilai dan perbaikan nama digabungkan menjadi satu pada menu prosedur agar pengguna mudah menemukan submenu tersebut.

\section{Rekomendasi Perbaikan pada Menu Prosedur}

Perbaikan yang dilakukan pada menu prosedur yaitu pemindahan sub menu perbaikan nilai dan perbaikan nama yang sebelumnya berada pada halaman dashboard. Gambar 3 berikut merupakan rancangan wireframe dari menu prosedur yang ada pada SIAK Undiksha ditinjau dari pengguna mahasiswa.

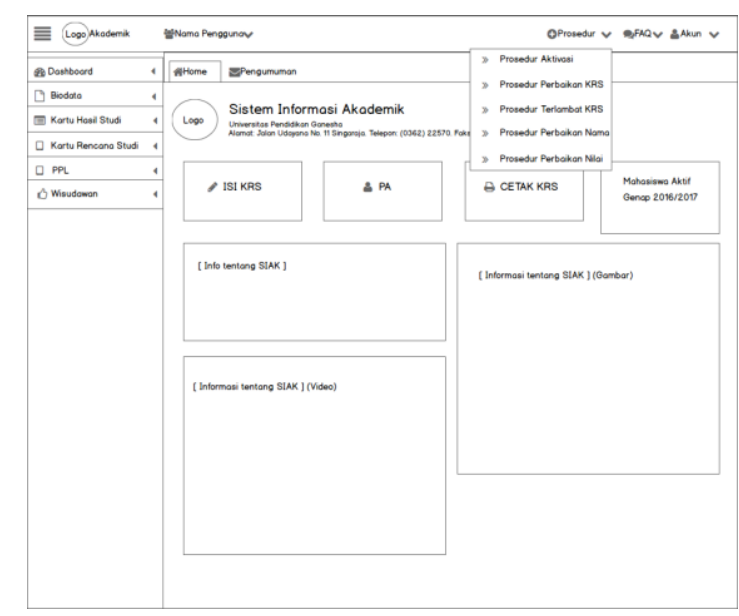

Gambar 3 Rancangan Wireframe pada Menu Prosedur

Dari hasil metode usability testing yaitu teknik performance measurement dan RTA diketahui jika pengguna kesulitan menemukan submenu perbaikan nilai yang sebelumnya berada pada halaman dashboard, dan pengguna juga menyarankan agar submenu perbaikan nilai tersebut dipindahkan agar memudahkan pengguna untuk menemukan submenu tersebut. Submenu perbaikan nilai dan perbaikan nama dipindahkan ke menu prosedur untuk 
menyamakan tempat dari menu-menu prosedur yang lainnya seperti prosedur aktivasi, prosedur perbaikan KRS dan prosedur terlambat KRS sehingga memudahkan pengguna dalam menemukannya. Dalam buku Don't Make Me Think (Krug, 2006), disebutkan bahwa hal-hal yang bertalian secara logis juga bertalian secara visual. Dimana hal-hal yang serupa dikelompokkan di bawah sebuah judul, menampilkannya dengan menggunakan sebuah gaya visual yang sama, atau meletakkannya dalam sebuah bidang yang didefinisikan dengan tegas.

\section{Rekomendasi Perbaikan pada Submenu Biodata}

Perbaikan yang dilakukan pada submenu biodata ada pada penghapusan tombol ubah biodata dan cetak biodata yang berada di bagian atas dan juga edit biodata langsung tanpa perlu ke halaman edit biodata. Gambar 4 berikut merupakan rancangan wireframe submenu biodata.

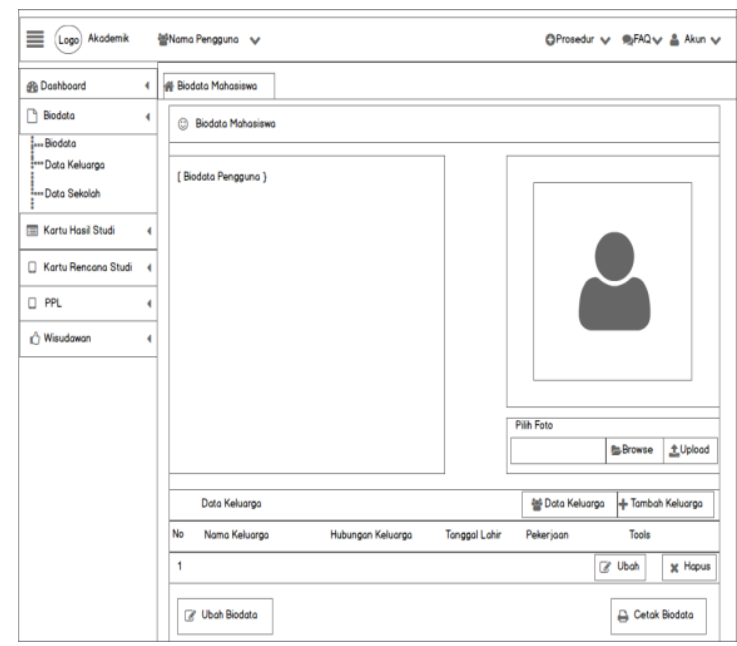

Gambar 4. Rancangan Wireframe Menu Biodata

Dari hasil teknik RTA tersebut, para pengguna sedikit kebingungan pada saat memilih tombol ubah biodata dan cetak biodata yang sebelumnya berada diatas dan dibawah halaman biodata mahasiswa. Tombol ubah biodata dan cetak biodata yang berada pada pojok kanan atas halaman biodata berwarna biru sama dengan warna background dibelakang menu tersebut yaitu biru, hal tersebutdapat mengganggu pengguna.
Sesuai dengan buku Don't Make Me Think (Krug, 2006) dimana hal tersebut merupakan gangguan latar belakang yang menghalangi pengguna untuk membaca cepat pada tulisan yang tertera pada tombol tersebut. Pengguna juga menyarankan agar tombol ubah dan cetak biodata tersebut berada dibawah halaman biodata mahasiswa sehingga sebelumnya pengguna dapat mengecek kesesuaian biodata dirinya kemudian baru mencetak ataupun mengubah biodata.

4. Rekomendasi Perbaikan pada Halaman Ubah Biodata

Rekomendasi perbaikan pada halaman ubah biodata yaitu perunahan tempat alert ketika pengguna berhasil melakukan penyimpanan biodata. Gambar 5 tersebut merupakan rekomendasi perbaikan pada halaman ubah biodata.

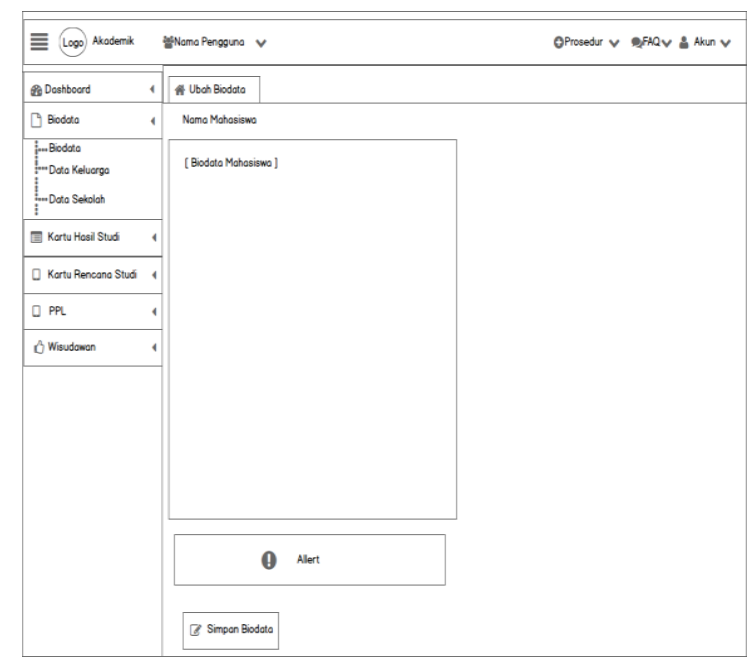

Gambar 5 Rancangan Wireframe pada Menu Ubah Biodata

Hasil dari teknik RTA yaitu beberapa pengguna menyarankan agar alert sukses pada saat menyimpan biodata diletakkan pada bagian bawah kolom biodata agar memudahkan pengguna mengetahui jika biodatanya tersebut sudah tersimpan. Sebelumnya alert sukses tersebut berada pada pojok kanan atas halaman ubah biodata sehingga pengguna kesulitan mengetahui jika biodata yang terubah sudah tersimpan, pengguna masih terpaku pada bagian bawah halaman ubah biodata pada tombol simpan biodata sehingga pengguna tidak mengecek ke bagian atas halaman tersebut. Hal tersebut tidak 
sesuai dengan teori $\mathrm{HCl}$ (Andrews, 2017) yang mensyaratkan kenyamanan dari pengguna dalam menggunakan sistem, sehingga perlu dilakukannya perubahan tempat dari alert tersebut agar pengguna lebih nyaman pada saat menggunakan sistem. Pada saat berhasil mengubah biodata tersebut seharusnya pengguna langsung diarahkan ke halaman form biodata awal sehingga pengguna bisa melihat jika biodatanya telah berhasil dirubah dan bisa langsung mencetak biodatanya apabila diperlukan.

\section{Rekomendasi Perbaikan pada Halaman Statistik Nilai Mahasiswa}

Perbaikan yang dilakukan pada halaman statistik nilai mahasiswa yaitu merubah posisi petunjuk statistik nilai mahasiswa. Gambar 6 berikut merupakan rekomendasi perbaikan pada halaman statistik nilai mahasiswa.

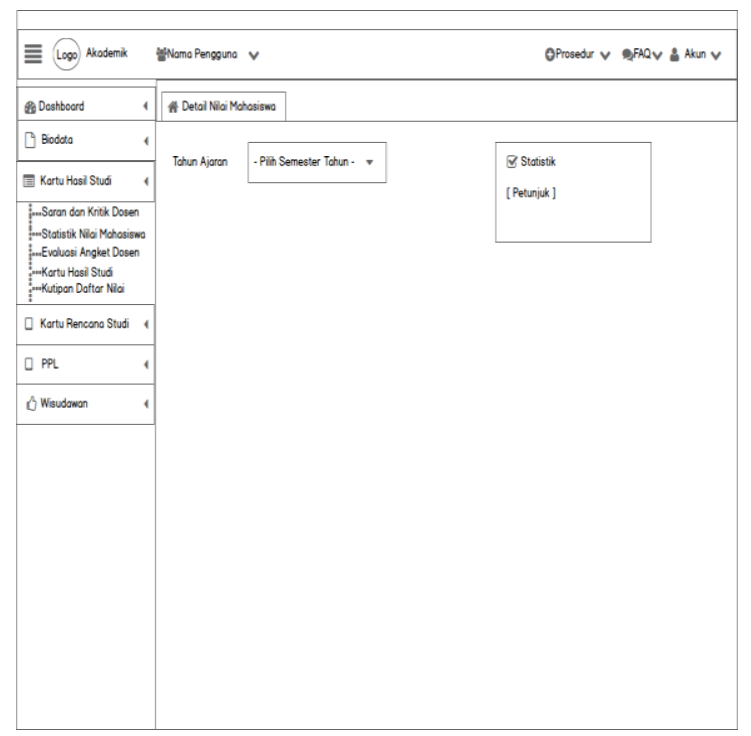

Gambar 6. Rancangan Wireframe pada Halaman Statistik Nilai Mahasiswa

Rekomendasi perbaikan pada halaman statistik nilai mahasiswa yaitu meletakkan petunjuk statistik nilai mahasiswa ke sebelah kanan tombol "pilih semester tahun", karena sebelumnya petunjuk statistik nilai mahasiswa tersebut berada pada bagian bawah tombol "pilih semester tahun" sehingga pada saat pengguna memilih semester tahun statistik nilai tersebut petunjuk dari statistik nilai mahasiswa tersebut jadi tertutup dan tidak terlihat. Hal tersebut juga mensyaratkan dari teori $\mathrm{HCl}$ (Andrews, 2017) yaitu kenyamanan pengguna pada saat menggunakan sistem, agar pengguna masih bisa membaca petunjuk statistic pada saat memilih semester tahun pada menu statistic nilai mahasiswa.

\section{Rekomendasi perbaikan pada Halaman Cetak Kartu Rencana Studi}

Perbaikan yang dilakukan pada halaman cetak kartu rencana studi yaitu pemilihan kata pada alert yang tertera pada saat pengguna mencetak KRS dan kelengkapannya. Gambar 7 tersebut merupakan rekomendasi perbaikan pada halaman cetak kartu rencana studi.

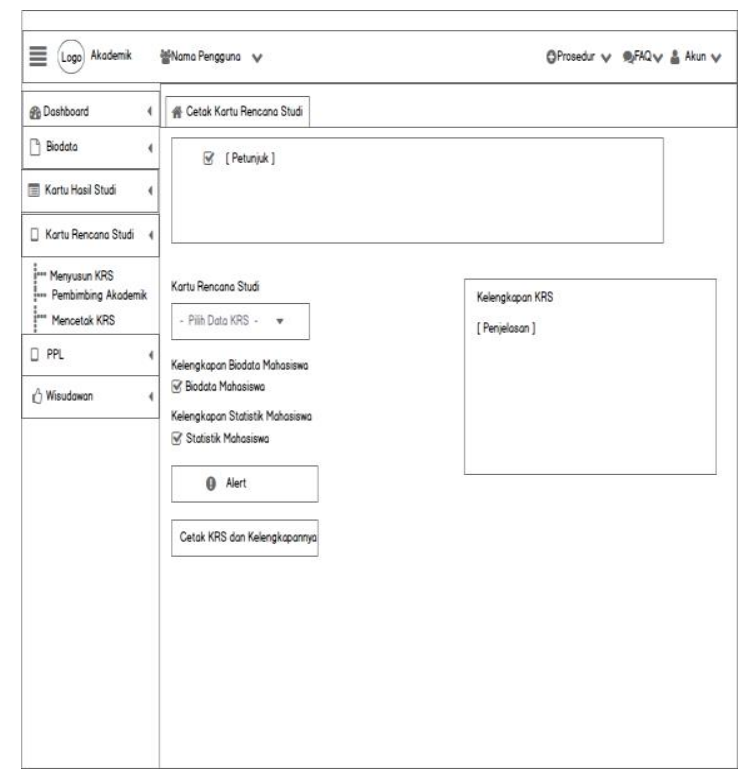

Gambar 7 Rancangan Wireframe pada Kartu Rencana Studi

Rekomendasi perbaikan halaman cetak kartu studi ini meruapakan hasil dari teknik RTA, dimana pengguna merasa agak sedikit kaget karena yang muncul tersebut berupa kata "warning" yang dibawahnya diikuti kalimat "tunggu sebentar, sedang mengolah data". Asumsi dari pengguna jika muncul kata "warning" maka terjadi kesalahan atau error, jadi untuk alert pada halaman cetak kartu rencana studi tersebut dihilangkan kata "warning" dan hanya diisi "tunggu sebentar, sedang megolah data". Hal tersebut dilakukan karena alert tersebut tidak sesuai dengan teori $\mathrm{HCl}$ yang mensyaratkan penggunaan error handling 
yang sopan untuk meningkatkan kenyamanan pengguna pada saat menggunakan sistem.

\section{SIMPULAN DAN SARAN}

Berdasarkan hasil penelitian yang dilakukan yaitu analisa user experience pada sistem informasi akademik Universitas Pendidikan Ganesha ditinjau dari pengguna mahasiswa dapat disimpulkan (1) dari hasil yang didapat dengan teknik performance measurement menunjukkan halaman SIAK Undiksha yang ditinjau dari pengguna mahasiswa secara umum sudah efektif. (2) jika dilihat dari hasil data yang didapatkan dari teknik performance measurement diketahui bahwa secara statistik waktu pengerjaan tugas responden kelompok pemula secara signifikan hamper sama dengan responden kelompok mahir, walaupun mean rank untuk responden kelompok mahir lebih cepat. Jadi secara umum halaman SIAK Undiksha yang ditinjau dari pengguna mahasiswa sudah efisien. (3) hasil data yang didapat dari teknik performance measurement menunjukkan jika responden masih melakukan kesalahan pada saat mengerjakan tugas, sehingga dapat dikatakan bahwa halaman SIAK Undiksha yang ditinjau dari pengguna mahasiswa masih membuat pengguna kesulitan pada saat menggunakan. (4) data kepuasan pengguna yang didapat dari hasil kuisioner SUS diketahui bahwa skor yang diperoleh kurang dari 68 yaitu sebesar 61.6, sehingga responden dikatakan belum puas pada saat menggunakan SIAK Undiksha yang ditinjau dari pengguna mahasiswa. Sebagian besar responden membutuhkan bantuan orang lain pada saat menggunakan SIAK Undiksha yang ditinjau dari pengguna mahasiswa, pengguna merasa sedikit kesulitan pada saat menggunakan beberapa menu yang ada pada SIAK Undiksha yang ditinjau dari pengguna mahasiswa.

Rekomendasi perbaikan dalam penelitian ini difokuskan untuk mengubah tata letak (layout) halaman dan menu navigasi yang menjadi penyebab kesalahan (error) pada pengguna. Selain itu saran yang didapat dari teknik RTA yaitu pengguna menyarankan perubahan bahasa dan istilah dan juga penyederhanaan bahasa pada beberapa menu. Perbaikan dilakukan dengan membiat wireframe halaman utama SIAK Undiksha yang ditinjau dari pengguna mahasiswa, halaman prosedur, halaman biodata, halaman ubah biodata, halaman statistik nilai mahasiswa dan halaman cetak kartu rencana studi.

Dari hasil penelitian yang diperoleh, maka peneliti memberikan saran-saran yaitu (1) untuk penelitian selanjutnya, untuk mengukur aspek usabilitydapat digunakan teknik lain dalam usability testing yaitu teknik Shadowing Method, Co-Discovery Learning, Coaching Method, Question Asking Protocol, Teaching Method, Remote Testing dan Eye Tracking. (2) untuk penelitian selanjutnya, dapat diteliti elemen lain selain usability yang menjadi bagian dari user experience tersebut seperti value (kebergunaan sistem), adoptability (kemudahan pada saat pemakaian pertama) dan desirability (kesenangan pengguna pada saat menggunakan), sehingga hasil penelitian lebih menyeluruh untuk user experience.

\section{DAFTAR RUJUKAN}

Andrews, K. (2017). Human-Computer Interaction, (May).

Bailey, B. (2013). FirstClick Usability Testing. Diambil 11 April 2017, dari http://webusability.com/firstclickusability-testing/

Dian, U., Siadin, N., Ardianto, H. W., \& Nuswantoro, U. D. (2008). MENGGUNAKAN METODE ANALISIS REGRESI LOGISTIK BINARI ( BINARY LOGISTIC REGRESSION ).

Farida, L. D. (2016). Pengukuran User Experience Dengan Pendekatan Usability [Kasus: Website Pariwisata Di Asia Tenggara]. Seminar Nasional Teknologi Informasi dan Multimedia, 6-7. 
Krug, S. (2006). Don't Make Me Think: A Common Sense Approach to Web Usability. Don't Make Me Think! A Common Sense Aproach to Web Usability. https://doi.org/10.1098/rspb.2009.161 4

Lestari, P. N., Santosa, P. I., \& Ferdiana, R. (2016). Pengukuran Pengalaman Pengguna Dalam Menggunakan Sistem Informasi Akademik. Sentika, 2016(Sentika), 18-19.

Mifsud, J. (2015). Usability Metrics - A Guide To Quantify The Usability Of Any System. Diambil 1 Juli 2017, dari http://usabilitygeek.com/usabilitymetrics-a-guide-to-quantify-systemusability/

Wiryawan, M. B. (2011). User Experience (UX) sebagai bagian dari pemikiran desain dalam pendidikan tinggi desain komunikasi visual. Humaniora, 2(2), 1158-1166. Diambil dari http://en.wikipedia.org/wiki/User_expe rience\#cite_ref-1. 